\title{
Modelling of Strengthening Mechanisms in Wrought Nickel-Based 825 Alloy Subjected to Solution Annealing
}

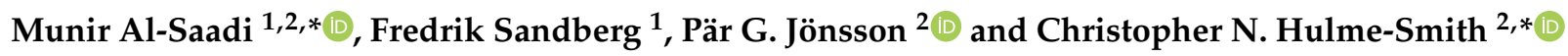 \\ 1 R\&D, AB Sandvik Materials Technology, SE-811 81 Sandviken, Sweden; fredrik.sandberg@sandvik.com \\ 2 Materials Science and Engineering, KTH Royal Institute of Technology, SE-100 44 Stockholm, Sweden; \\ parj@kth.se \\ * Correspondence: munir.al-saadi@sandvik.com or muniras@kth.se (M.A.-S.); chrihs@kth.se (C.N.H.-S.)
}

Citation: Al-Saadi, M.; Sandberg, F.; Jönsson, P.G.; Hulme-Smith, C.N. Modelling of Strengthening Mechanisms in Wrought Nickel-Based 825 Alloy Subjected to Solution Annealing. Metals 2021, 11, 771. https://doi.org/10.3390/ met11050771

Academic Editor: Martin Heilmaier

Received: 11 April 2021

Accepted: 4 May 2021

Published: 7 May 2021

Publisher's Note: MDPI stays neutral with regard to jurisdictional claims in published maps and institutional affiliations.

Copyright: (c) 2021 by the authors. Licensee MDPI, Basel, Switzerland. This article is an open access article distributed under the terms and conditions of the Creative Commons Attribution (CC BY) license (https:/ / creativecommons.org/licenses/by/ $4.0 /)$.

\begin{abstract}
Wrought nickel-based Alloy 825 is widely used in the oil and gas industries, attributed to its high strength at temperatures up to $540{ }^{\circ} \mathrm{C}$. However, differences in mechanical properties arise in finished components due to variations in both grain size and dislocation density. Numerous experimental studies of the strengthening mechanisms have been reported and many models have been developed to predict strengthening under thermomechanical processing. However, there are debates surrounding some fundamental issues in modeling and the interpretation of experimental observations. Therefore, it is important to understand the evolution of strain within the material during the hot-forging process. In addition, there is a lack of research around the behavior during hot deformation and subsequent stabilization of Alloy 825. This article investigates the origin of this strength and considers a variety of strengthening mechanisms, resulting in a quantitative prediction of the contribution of each mechanism. The alloy is processed with a total forging strain of $0.45,0.65$, or 0.9 , and subsequent annealing at a temperature of $950^{\circ} \mathrm{C}$, reflecting commercial practice. The microstructure after annealing is similar to that before annealing, suggesting that static recovery is dominant at this temperature. The maximum yield strength and ultimate tensile strength were $348 \mathrm{MPa}$ and $618 \mathrm{MPa}$, respectively, obtained after forging to a true strain of 0.9 , with a ductility of $40 \%$. The majority of strengthening was attributed to grain refinement, the dislocation densities that arise due to the large forging strain deformation, and solid solution strengthening. Precipitate strengthening was also quantified using the Brown and Ham modification of the Orowan bowing model. The results of yield strength calculations are in excellent agreement with experimental data, with less than $1 \%$ difference. The interfacial energy of $\operatorname{Ti}(C, N)$ in the face-centered cubic matrix of the current alloy has been assessed for the first time, with a value of $0.8 \mathrm{mJm}^{-2}$. These results can be used by future researchers and industry to predict the strength of Alloy 825 and similar alloys, especially after hot-forging.
\end{abstract}

Keywords: Alloy 825; strain level; strength properties; annealing; strengthening mechanisms

\section{Introduction}

Alloy 825 is a nickel-based alloy that is typically cast into a final shape, or is supplied as bars that are wrought, hot finished and annealed [1-3]. It is currently used for various applications, such as pickling tanks and vessels [4], in the oil and gas industries [5], agitators [6], and heat exchanger systems [7]. The components in these applications are subjected to a complex combination of elevated temperatures, high stress, and hostile environmental conditions [8]. Alloy 825 exhibits exceptional corrosion resistance and strength properties up to at least $540{ }^{\circ} \mathrm{C}$ [9]. The high contents of nickel, chromium and molybdenum give good corrosion resistance and improve the mechanical properties such as the yield strength, ultimate tensile strength and elongation to failure [5,6,8-10]. According to industrial standards, the target for the hot-annealed material is an alloy with a room temperature yield strength of $\sigma_{\mathrm{y}} \geq 241 \mathrm{MPa}$ [1]. 
The alloy, which contains small additions of titanium, is expected to form a matrix of a face-centered cubic (austenitic) phase containing small amounts of titanium carbonitride. The casting structure from when the alloy was first made is broken down by thermomechanical processing to obtain a uniform chemistry and microstructure. After forging, the material is then solution annealed (or stabilized) to precipitate the maximum volume fraction of $\operatorname{Ti}(\mathrm{C}, \mathrm{N})$ inside grains, and thereby avoid the precipitation of $\mathrm{Cr}_{23} \mathrm{C}_{6}$-type carbides at grain boundaries at later stages of the thermomechanical treatment [11,12]. $\mathrm{Cr}_{23} \mathrm{C}_{6}$-type carbides would deplete the matrix of chromium, which could lead to sensitization to corrosive attack.

While Alloy 825 subjected to hot processing has good high-temperature strength properties up to $540{ }^{\circ} \mathrm{C}$, the yield strength drops to $176 \mathrm{MPa}$ above this temperature [13]. This is due to changes that occur during thermomechanical processing of the billet that lead to a sub-optimum grain size distribution and precipitate population. In forged products of Alloy 825, work hardening, recovery, and recrystallization are possible during hotforging and soft annealing [8,14-19]. It is well known that recrystallization generates fine grains, which are beneficial for both strength and toughness [20-22]. Differences in the grain size within the material are often observed due to inhomogeneous local strains [23]. This can lead to differences in mechanical properties due to variations in both grain size and dislocation density. Therefore, it is important to understand the evolution of strain within the material during the hot-forging process. However, there is a lack of research focusing on the behavior during the hot deformation and subsequent stabilization of Alloy 825. A few studies exist, but they have only focused on the dynamic recrystallization of Alloy 825 during hot deformation at very high reduction ratios (true strain, $\varepsilon_{\mathrm{t}}$ : $0.7 \leq \varepsilon_{\mathrm{t}} \leq 2.5$ ) [19]. The current work addresses this deficiency by examining the effects of lower industrially relevant reduction ratios on mechanical properties, based on microstructural changes. The basic important strengthening mechanisms, including Peierls stress, dislocation strengthening, grain size (Hall-Petch) strengthening, solid solution strengthening, and precipitation hardening, will be analyzed, and the experimental and calculated yield strength in annealed alloy will be reviewed.

In the case of multicomponent alloys, solid solution strengthening due to multiple alloying additions has been the subject of many theoretical studies [24,25]. Thus, the effect of solid solution strengthening has been included from these calculations as the variation in the composition of the concentration matrix under the heat treatment conditions examined; the solid solution strengthening was determined to be significant. The Gypen and Deruyttere [25-27] model has been applied to describe the contribution of solid solution strengthening to the measured yield strength of Alloy 825 .

In the case of precipitation hardening, the strengthening contribution of secondphase particles depends on the alloying system, size and volume fraction of the particles, as well as the nature of the interaction between dislocation and particles [28]. If the precipitates are large and very strong, Orowan bowing is the relevant strengthening. When the precipitates are smaller and weak, cutting or the Friedel mechanism controls the strengthening contribution of precipitates [28]. Finally, dislocations can also pass the precipitates via cross-slip and climb [29]. In the current case, the precipitates are themselves very strong and likely to be fine, so precipitate cutting is unlikely [28,30-33]. Dislocation climb is mediated by diffusion and requires a significant time to occur, so bowing is likely to be the limiting mechanism.

In the case of structural strengthening, it is difficult to separate the effects of work hardening from those due to grain refinement, as both the grain size and dislocation density will vary simultaneously due to deformation and recrystallization that occurs during the hot-forging process $[20,21,23,34]$. Dynamic recovery will also occur during hot deformation, in competition with recrystallization, which reduces the dislocation density independently of the grain size. In alloys and scenarios similar to the current study, the contribution of dislocations to yield strength is well-known and accepted [35]. Given the typical grain sizes in similar alloys subjected to similar processing, it is expected that strengthening will follow 
the Hall-Petch relationship [36-41]. Since the grain size and dislocation density depend on each other, it is reasonable to consider these effects together. A modified expression for yield strength in an austenitic stainless steel that takes into account both contributions has been published $[19,36,42,43]$.

The primary objectives of the present work are to quantify the strengthening mechanisms in Alloy 825 during soft annealing (stabilization) and to compare these findings to tensile test data. The effects of forging strain magnitude and subsequent annealing on the microstructure, strengthening mechanisms and room temperature mechanical properties will be investigated to assess the suitability of current industrial practice.

\section{Materials and Methods}

\subsection{Materials Used and Thermomechanical Treatment}

Samples of Alloy 825 were manufactured from one ingot starting from melting in the electric arc furnace, followed by refinement in an argon oxygen decarburization converter and pouring into molds in which the melt was allowed to air-cool and solidify. The ingot was then subjected to hot-forging at $1200{ }^{\circ} \mathrm{C}$ with a total $70 \%$ reduction to obtain three billets, which served as the starting billets for the subsequent hot-forging and annealing experiments. The chemical composition of the material produced with the above-described melting practice is presented in Table 1 . The starting billets were subsequently hot-forged at $1200{ }^{\circ} \mathrm{C}$ to true strains of $0.45,0.65$ or 0.90 , (Figure 1, Table 2).

Table 1. Chemical composition of Alloy 825 used in the current investigation (wt. \%). Combustion analysis was used for carbon and nitrogen and X-ray fluorescence spectrometry was used for all other elements in accordance with the relevant standards.

\begin{tabular}{lcccccccccc}
\hline Element & $\mathbf{C}$ & $\mathbf{S i}$ & $\mathbf{M n}$ & $\mathbf{C r}$ & $\mathbf{F e}$ & $\mathbf{M o}$ & $\mathbf{T i}$ & $\mathbf{C u}$ & $\mathbf{N}$ & $\mathbf{N i}$ \\
\hline Current & 0.02 & 0.20 & 0.800 & 22.00 & balance & 3.000 & 0.700 & 1.800 & 0.018 & 41.5 \\
Uncertainty & 0.01 & 0.01 & 0.001 & 0.03 & & 0.003 & 0.002 & 0.005 & 0.001 & 0.03 \\
\hline
\end{tabular}

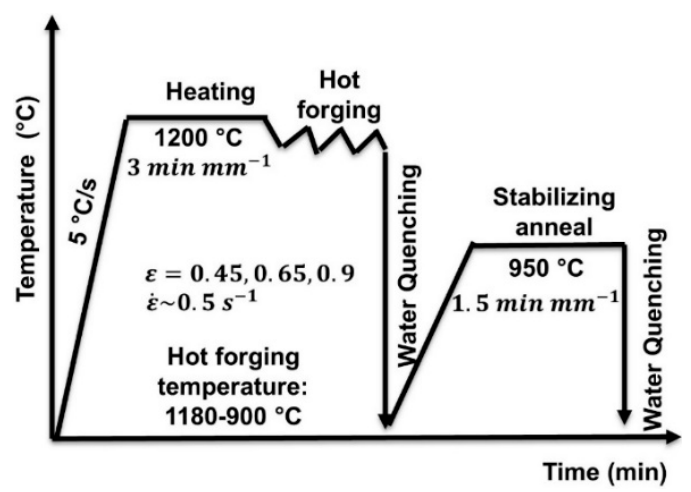

Figure 1. Schematic diagram showing the thermomechanical processing cycle and soft annealing process. "min $\mathrm{mm}^{-1}$ " refers to the heat treatment time per millimeter of rod radius.

Table 2. Sample designations used in the present work.

\begin{tabular}{cccc}
\hline Sample Designation & A & B & C \\
\hline True strain & 0.45 & 0.65 & 0.90 \\
\hline
\end{tabular}

After forging, the bars were solution annealed at a temperature of $950{ }^{\circ} \mathrm{C}$ for $1.5 \mathrm{~min}$ per millimeter of bar radius. From each annealed bar, samples were extracted for microscopy in the parallel to the forging (axial) direction from the center of the solid bar. 


\subsection{Microstructure Evolution}

\subsubsection{Scanning Electron Microscopy (SEM)}

A Zeiss Sigma field emission SEM (Carl Zeiss Microscopy GmbH, Oberkochen, Germany) equipped with TSL OIM Analyzer software version 7 (AMETEK, Inc., Berwyn, PA, USA) was used to perform microstructural investigations of samples after tensile testing. A step size of $0.5 \mu \mathrm{m}$ for higher-resolution local scans was used to characterize the overall microstructure and then subjected to a clean-up procedure, in which only pixels with a confidence index $\geq 0.1$ were accepted. The operating voltage was $20 \mathrm{kV}$. Energy dispersive $\mathrm{X}$-ray spectroscopy (EDS) was also performed to analyze compositions.

Samples for microstructural investigations were mounted in phenolic resin and prepared using standard grinding and polishing procedures. EBSD samples for SEM-EBSD analysis were ground and polished to a final step of $0.05 \mu \mathrm{m}$ colloidal silica. Samples were then electrolytically polished at temperatures between $8{ }^{\circ} \mathrm{C}$ and $18{ }^{\circ} \mathrm{C}$ in a $3 \mathrm{M} \mathrm{H}_{2} \mathrm{SO}_{4}$ ethanol solution $\left(630 \mathrm{~mL}\right.$ ethanol, $123 \mathrm{~mL} \mathrm{H}_{2} \mathrm{SO}_{4}$, both from Merck KGaA, Darmstadt, Germany). The electrolytic polishing voltage was $30 \mathrm{~V}-40 \mathrm{~V}$, with a current of $1 \mathrm{~A}-2 \mathrm{~A}$, and the polishing took approximately $30 \mathrm{~s}$. The areas of observation in this study were in the center of each sample.

Electron backscatter diffraction (EBSD) was performed, and grain orientation was assessed by using "TSL OIM Analyzer" software. The average confidence index, CI (a measure of the fraction of the Kikuchi bands indexing reliability), of the diffraction patterns in each scan was approximately 0.96 . The grain size was evaluated using a linear intercept method along the forging direction. For each sample, at least three EBSD scans with a size step of $3.0 \mu \mathrm{m}$ were acquired, covering an area of $2319 \mu \mathrm{m} \times 1737 \mu \mathrm{m}\left(\sim 4.03 \mathrm{~mm}^{2}\right)$. To ensure statistically representative results, a minimum of 3000 grains were measured in each sample.

The fraction of recrystallized grains was quantified using grain orientation spread (GOS). This is defined as the mean difference between the grain orientation at each point within a grain and the mean orientation of that grain is chosen based on a grain tolerance angle of $5^{\circ}$ [43-45]. This means that all pixels that exhibited an orientation within $5^{\circ}$ of their nearest neighbors were considered to belong to the same grain [44]. Grains with a GOS $\leq 1^{\circ}$ were considered to be recrystallized, while the rest were considered to be deformed [43,46-50].

The TSL OIM Analyzer software was also used to identify twin boundaries in order to exclude them from grain size calculations. Twin boundaries were defined when the misorientation angle $\theta_{\mathrm{m}}=60^{\circ}$ and the local orientation lies within $5^{\circ}$ of a $\langle 111\rangle$ axis. It is necessary to exclude twins from grain size calculations, as annealing twins $(\Sigma 3)$ do not contribute to strengthening in this alloy $[44,45]$.

The dislocation density can be estimated from EBSD data by using Frank's equation (Equation (1), where $\kappa$ is a constant that depends on the geometry of the boundaries, $\theta_{\mathrm{KAM}}$ is the kernel average misorientation expressed in radians, $b$ is the Burgers vector and $s$ is the step size of the EBSD scan) [51-53]. The kernel average misorientation (KAM) is the average difference in orientation between a fixed measurement point and its nearest neighbors, used to characterize the nature of a boundary when the measurement point lies on that boundary. $\kappa=2$ represents pure tilt boundaries and $\kappa=4$ represents pure twist boundaries [53]. Some studies use $\kappa=2 \sqrt{ } 3$, as this relates the EBSD step size to the (hexagonal) surface area that is closest to each step location [51,52]. In this study, $\kappa=2$, as the forging deformation under consideration leads overwhelmingly to the formation of tilt boundaries [54-56]. The dislocation density may, therefore, be calculated from values that are either known $(\kappa, b, s)$ or may be measured $\left(\theta_{\mathrm{KAM}}\right)$. The kernel average misorientation gives an overestimate of dislocation density because of the presence of lowangle dislocation sub-boundaries that are grain boundaries in practice but are included in the dislocation density calculation [51,52]. All parameters used for the EBSD measurements 
were kept the same. For each sample, at least three EBSD scans with a size step of $0.75 \mu \mathrm{m}$ were acquired, covering an area of $578.5 \mu \mathrm{m} \times 434 \mu \mathrm{m}\left(\sim 0.25 \mathrm{~mm}^{2}\right)$.

$$
\rho=\kappa \theta_{\mathrm{KAM}}(b s)^{-1}
$$

\subsubsection{Mechanical Properties}

Round bar specimens with $10 \mathrm{~mm}$ diameters and $50 \mathrm{~mm}$ gauge length were subjected to room temperature tensile testing parallel to the forging direction at a strain rate of $0.001 \mathrm{~s}^{-1}$ on a screw-driven Instron 4488 electromechanical tensile test machine (Instron Ltd., Norwood, MA, USA). The yield strength $\left(\sigma_{\mathrm{y}}\right)$, ultimate tensile strength $\left(\sigma_{\mathrm{UTS}}\right)$, and total elongation at failure $\left(\varepsilon_{\mathrm{f}}\right)$ were determined using a measurement system. Three tensile samples were used for each deformation condition to quantify uncertainty and increase confidence in the results.

\section{Theoretical Prediction of Phases and As-Stabilized Yield Strength}

\subsection{Microstructure Evolution}

The equilibrium phase fractions were calculated as a function of temperature for the measured composition (Table 1) using Thermo-Calc simulation software, version 2020a with the TCNI9 thermodynamic database (Thermo-Calc Software AB, Solna, Sweden). Only phases permitted by default were included in the calculation. Similarly, all phases rejected by default were excluded. The alloy is expected to form a matrix of face-centered cubic phase, with small amounts of titanium carbonitride and alumina in the temperature range $900<\mathrm{T} /{ }^{\circ} \mathrm{C}<1300$ (Figure 2) [11]. However, the alumina is unlikely to form in significant quantities, as this requires all oxygen in the material to react with aluminum. While this is thermodynamically favorable, it is unlikely that this process will be completed during the time scale of the heat treatment. The same is true of titanium carbonitride. However, since it is expected to form a quantity that is an order of magnitude greater than alumina, it is feasible that titanium carbonitride will be detected following forging. The material is water-quenched immediately after forging and so it is expected that the transformations below $900^{\circ} \mathrm{C}$ indicated by Figure 2 will be avoided. Therefore, the as-forged material is expected to consist almost entirely of a face-centered cubic phase containing a small amount of titanium carbonitride and trace amounts of alumina. Large particles $(>1 \mu \mathrm{m}$, referred to as "inclusions" [57]) will be ignored as they have no significant effect on the mechanical properties [12]. Additionally, the small titanium carbonitrides are the only phase that will be considered for coarsening in this study: the face-centered cubic phase is the matrix phase and alumina is ignored [58].

At the soft annealing temperature of $950{ }^{\circ} \mathrm{C}$, titanium carbonitride is expected to be stable and will precipitate further and grow (Figure 2). Prolonged annealing at this temperature is intended to maximize the amount of titanium carbonitride that is formed. Therefore, it is expected that the as-stabilized microstructure consists predominantly of the face-centered cubic matrix phase, containing titanium carbonitride in greater quantities than in the samples directly after forging, in which the transformation of titanium carbonitrides is likely to be incomplete. An example of a scanning electron micrograph taken in backscatter mode shows titanium carbonitride precipitates, $\operatorname{Ti}(\mathrm{C}, \mathrm{N})$, in the grain body and at a grain boundary in sample A (Figure 3). Two of these particles were analyzed using energy dispersive $\mathrm{X}$-ray spectroscopy. The precipitates were rich in titanium, nitrogen, and carbon, with small amounts of other elements also detected from spectrum 2 (Table 3). 


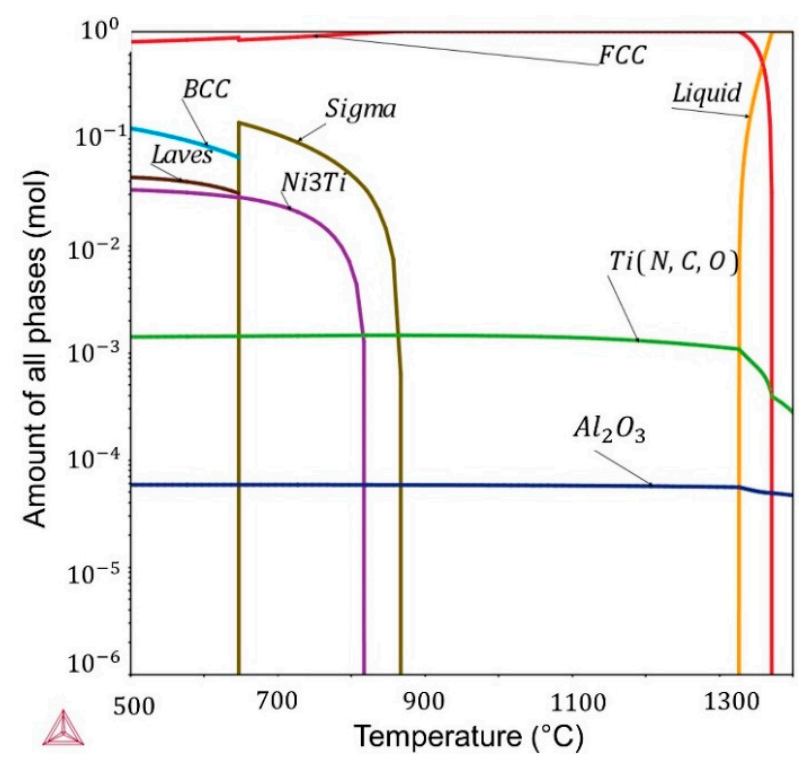

Figure 2. Temperature dependence of equilibrium amount of all phases in one mole of Alloy 825 . "FCC" is a nickel-rich face-centered cubic phase, "BCC" is a body-centered cubic phase with the approximate composition $\mathrm{M}(\mathrm{C}, \mathrm{N})_{3}$, "sigma" and "laves" are intermetallic phases, other phases have the approximate chemistries specified in the corresponding labels.

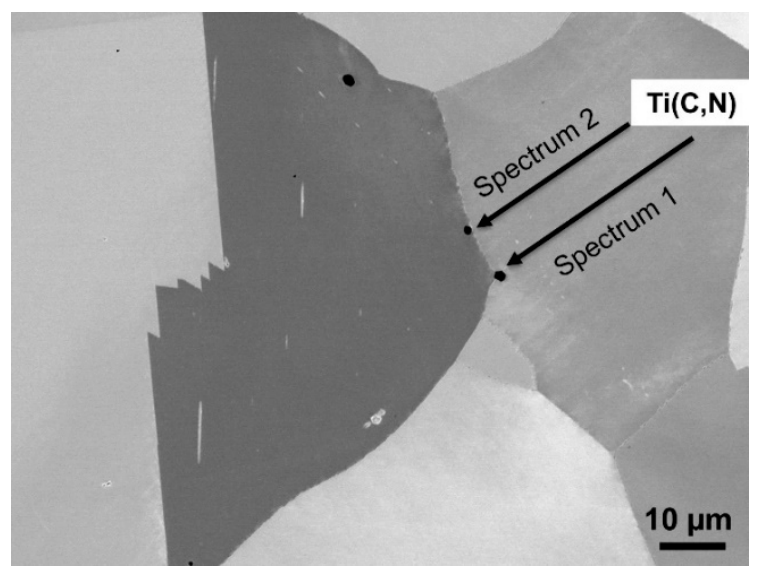

Figure 3. Scanning electron micrograph of the morphology of a titanium carbonitride precipitate in the grain boundary and interior.

Table 3. Chemical compositions, in wt. \%, of the precipitates depicted in Figure 3, measured using energy dispersive $\mathrm{X}$-ray spectroscopy.

\begin{tabular}{cccccccc}
\hline Element & $\mathbf{T i}$ & $\mathbf{N}$ & $\mathbf{C}$ & $\mathbf{C r}$ & $\mathbf{F e}$ & $\mathbf{N i}$ & $\mathbf{M o}$ \\
\hline Spectrum 1 & $80 \pm 0.2$ & $12.7 \pm 0.2$ & $7.3 \pm 0.1$ & & & & \\
Spectrum 2 & $67.8 \pm 1.3$ & $10.8 \pm 0.3$ & $6.3 \pm 0.2$ & $9.2 \pm 1.7$ & $2.7 \pm 0.4$ & $2.3 \pm 0.2$ & $0.9 \pm 0.2$ \\
\hline
\end{tabular}

It is also reasonable to expect that small amounts of other phases could form during the heating of the sample from room temperature to the stabilization temperature, but such phases are neglected in this study.

In the current experiments, the rods after forging were $18 \mathrm{~mm}$ in radius, so the soft annealing time was 27 min (Figure 1). A precipitation simulation using Thermo-Calc PRISMA 2020a allows the precipitate size after stabilization at $950{ }^{\circ} \mathrm{C}$ for $27 \mathrm{~min}(1620 \mathrm{~s})$ to be calculated. As a simplification, heating and cooling were assumed to be rapid enough that precipitation and growth during heating and cooling could be neglected. Ti(C,N) 
precipitates were allowed to nucleate on dislocations, grain boundaries, and in the bulk of the matrix, which was modeled as the face-centered cubic phase with the nominal composition of the alloy (Figure 2, Table 1). Since the nucleation sites are not known, the average of all three types of site will be taken. The dislocation density, grain size and grain aspect ratio must be known. These may be measured in the as-forged condition or estimated from values typical of similar alloys subjected to similar thermomechanical treatments to estimate the availability of grain boundaries and dislocations as nucleation sites in the early stages of the stabilization heat treatment. It is likely that recovery, recrystallization and grain growth may occur during the stabilization treatment, but nucleation is likely to occur at the early stages of the heat treatment, before these processes can occur to a significant extent. For grain boundary precipitation, a wetting angle must be specified for the precipitate. This was assumed to be $90^{\circ}$, in line with previous studies $[59,60]$.

To provide a physical description of nucleation and growth, the interfacial energy between the precipitate and the matrix must be known. However, there are no data for this in the literature. Thermo-Calc is able to simulate interfacial energies based on Becker's bond energy approach [61]. The model only accounts for body- and face-centered cubic crystals, which is sufficient in this case, since both the matrix and precipitates have a facecentered cubic crystal structure. Calculation of the interfacial energy using the chemistries of the matrix and precipitate taken from the equilibrium calculation (Figure 2) predicts that the interfacial energy is approximately $0.8 \mathrm{~J} \mathrm{~m}^{-2}$ and is weakly dependent on the chemistry of the precipitate (Figure 4a). A value of $0.8 \mathrm{~J} \mathrm{~m}^{-2}$ was then used in the precipitation calculations. The interfacial energy of similar $\mathrm{Ti}(\mathrm{C}, \mathrm{N})$ precipitates in austenitic steels (8R70 and ASTM 316Ti) has been shown to be lower but of a similar magnitude $\left(0.2 \mathrm{~J} \mathrm{~m}^{-2}\right.$ to the current result [12].

A first estimation of the precipitation behavior may be calculated using the chemistries already calculated, the interfacial energy derived and reasonable estimates of other critical quantities: a grain size of $50 \mu \mathrm{m}$, a grain aspect ratio of $1[59,60]$ and a dislocation density of $5 \times 10^{12}[59,60,62]$. The average precipitate radius, $r_{\mathrm{p}}$, is expected to be $39 \mathrm{~nm}$ after the total heat treatment time (1620 s) (Figure $4 \mathrm{~b}$ ). Additionally, the volume fraction, $f_{\mathrm{p}}$, reaches the equilibrium value within the first $90 \mathrm{~s}$ of the treatment (Figure 4c).

\subsection{As-Stabilized Mechanical Properties}

Following stabilization, there are several mechanisms that can affect the strength of Alloy 825 (Equation (2)). The first of these is the Peierls stress of the matrix phase, $\sigma_{\mathrm{p}}$. Contributions may also be made by solid solution strengthening, $\sigma_{\mathrm{s}}$, Orowan bowing around precipitates in the matrix, $\sigma_{\mathrm{O}}$, grain refinement, $\sigma_{\mathrm{g}}$, and work hardening, $\sigma_{\mathrm{w}}$. These contributions may be summed to give the total yield strength, $\sigma_{\mathrm{y}}$ of the material [35]. The value of $\beta$ has been shown to be $1 \leq \beta \leq 2$ depending on the precipitates present. In the current case, without ordered precipitates, a value of $\beta=1$ has been used in previous studies [63].

$$
\sigma_{\mathrm{y}}=\left(\sigma_{\mathrm{p}}^{\beta}+\sigma_{\mathrm{s}}^{\beta}+\sigma_{b}^{\beta}+\sigma_{\mathrm{g}}^{\beta}+\sigma_{\mathrm{w}}^{\beta}\right)^{1 / \beta}
$$

\subsubsection{Peierls Stress}

For face-centered cubic pure nickel, Peierls stress (or lattice friction) has been calculated to be approximately $3 \mathrm{MPa}[64]$. 

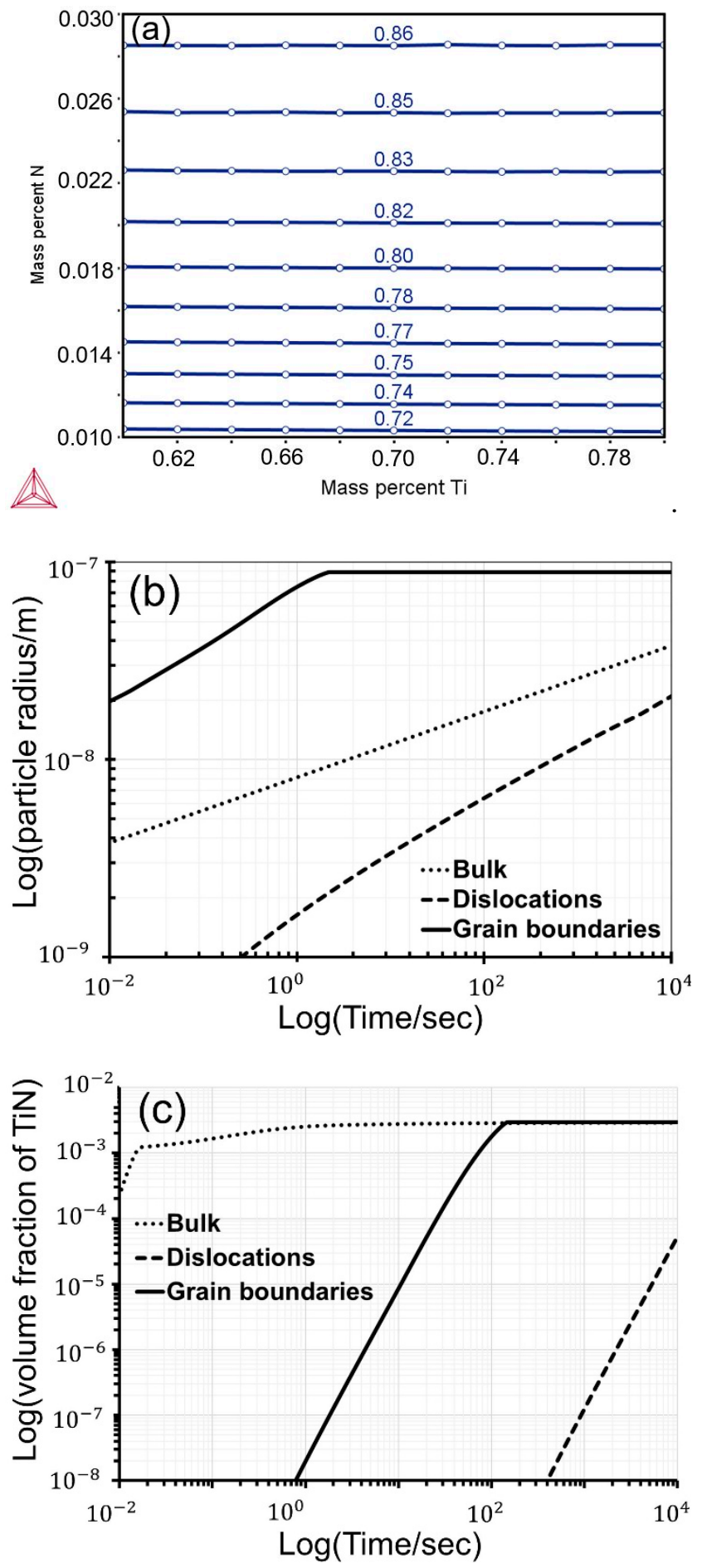

Figure 4. (a) A contour plot showing the calculation results comparing the titanium content to that of nitrogen, (b) the calculated mean particle radius and (c) volume fraction of the observed Ti(N,C) from Thermo-Calc Prisma at a temperature of $950{ }^{\circ} \mathrm{C}$ for the time periods up to $10^{4} \mathrm{~s}$.

\subsubsection{Solution Strengthening}

The majority of the material is expected to be the nickel-rich face-centered cubic matrix. Therefore, the solid solution strengthening of this phase will have a significant effect on the yield strength of the material. It is possible to estimate solid solution strengthening, based on concentrations of solutes using the multi-component Labusch equation extended by Gypen and Deruyttere [25-27] (Equation (3)), where $f_{\mathrm{p} \text {,tot }}$ is the total volume fraction of precipitates, $x_{i}$ is the atomic fraction of the $i^{\text {th }}$ solute and $\psi_{i}$ is the solution strengthening 
coefficient of the $i^{\text {th }}$ solute. The values of $\psi_{i}$ are estimated from the shear modulus and atomic size of the $i^{\text {th }}$ element: $\psi_{i}=\frac{3}{2} G\left(\eta_{i}+16 \delta_{i}\right)^{3 / 2}$, where the shear modulus of Alloy $825, G=76 \mathrm{GPa}$ [9], $\eta_{i}=g_{i} /\left(1+0.5 g_{i}\right) \cdot g_{i}=\left|\frac{G_{i}-G_{\mathrm{Ni}}}{G_{\mathrm{Ni}}}\right|, G_{i}$ is the shear modulus of element $i, G_{\mathrm{Ni}}$ is the shear modulus of nickel [65] and the lattice strain, $\delta_{i}=\frac{r_{i}-r_{\mathrm{Ni}}}{r_{\mathrm{Ni}}}$, where $r_{i}$ is the atomic radius of element $i$ and $r_{\mathrm{Ni}}$ is that of nickel [66]. $G_{\mathrm{Ni}}=80 \mathrm{GPa}$ and $r_{\mathrm{Ni}}=0.117 \mathrm{~nm}$, $G_{i}$ and $r_{i}$ are obtained from the literature [67].

$$
\sigma_{\mathrm{s}}=\left(1-f_{\mathrm{p}, \text { tot }}\right)\left(\sum_{i=1}^{i} \psi_{i}^{2 / 3} x_{i}\right)^{3 / 2}
$$

Since the fraction of precipitates will be of the order of 0.19 at. $\%$, it is reasonable to approximate the concentrations of the matrix phase as the bulk composition and to assume that $(1-f) \approx 1$. Using these concentrations, together with strengthening coefficients from the literature, it is possible to estimate the contribution to yield strength to be $127 \mathrm{MPa}$ (Table 4).

Table 4. Strengthening coefficients for solid solution strengthening in nickel $[25,63]$.

\begin{tabular}{|c|c|c|c|c|c|c|c|c|}
\hline Element & Al & Si & $\mathrm{Fe}$ & $\mathrm{Cr}$ & Mo & Mn & Ti & $\mathrm{Cu}$ \\
\hline Concentration/at. \% & 0.19 & 0.38 & 31.01 & 24.25 & 1.81 & 0.86 & 0.88 & 1.37 \\
\hline $\begin{array}{c}\text { Strengthening } \\
\text { coefficient } \psi_{i} / \mathrm{MPa}\end{array}$ & 202 & 119 & 160 & 356 & 1057 & 209 & 358 & 326 \\
\hline
\end{tabular}

\subsubsection{Work Hardening and Grain Refinement}

The effect of dislocation density on yield strength is well understood (Equation (4) [35], where $\sigma_{\mathrm{y}}$ is the yield stress; $\tau_{0}$ is the critical resolved shear stress for dislocation motion (i.e., without the effects of other dislocations, which the material will also exhibit when there is a low dislocation density, in which case $\tau_{0}=\left(\sigma_{\mathrm{P}}+\sigma_{\mathrm{S}}+\sigma_{\mathrm{O}}\right) / \mathrm{M} ; \alpha$ is a proportionality constant and depends on the strain rate (dislocation density) and the temperature [42]; $M$ is the Taylor factor, approximately equal to 3.1 [68]; $G=7.6 \times 10^{10} \mathrm{~Pa}$ is the shear modulus [9] and $b=2.54 \times 10^{-10} \mathrm{~m}$ is the Burgers vector). The dependence of yield strength on the square root of dislocation density can be found by differentiation and is approximately $60 \alpha$ MPa $\mathrm{m}^{-1}$ (Equation (5)).

$$
\begin{gathered}
\sigma_{\mathrm{y}}=M\left(\tau_{0}+\alpha G b \rho^{1 / 2}\right) \\
\frac{\mathrm{d} \sigma_{\mathrm{y}}}{\mathrm{d} \rho^{1 / 2}}=M \alpha G b \approx 60 \alpha
\end{gathered}
$$

A material that is heavily worked and then subjected to extensive annealing typically exhibits a dislocation density $\sim 10^{12} \mathrm{~m}^{-2}$ [62], while for a fully recrystallized material, dislocation density is often approximated to $\sim 10^{10} \mathrm{~m}^{-2}$. Heavily cold-worked materials have a dislocation density of the order of $10^{15} \mathrm{~m}^{-2}$, which is often taken as an upper bound of the dislocation density in any metal. Taking this upper bound and the highest value of $\alpha=0.5$ [62] shows that work hardening should be expected to contribute up to $100 \mathrm{MPa}$ to the yield stress.

Given the typical grain sizes in similar alloys subjected to similar processing $[69,70]$, it is expected that the grain size of the current samples will be such that the grain size strengthening will follow the Hall-Petch relationship (Equation (6), where $\sigma_{\mathrm{y}}$ is the yield strength, $\sigma_{0}$ is the yield strength attributed to other strengthening mechanisms, i.e., the yield strength of the material in the very large-grained condition, equal to $\sigma_{\mathrm{P}}+\sigma_{\mathrm{S}}+\sigma_{\mathrm{O}}$ in the current study, $K_{\mathrm{g}}$ is the Petch coefficient, and $d$ is the grain size and is expected to be between $1 \mu \mathrm{m}$ and $100 \mu \mathrm{m})$ [37-41].

$$
\sigma_{\mathrm{y}}=\sigma_{0}+K_{\mathrm{g}} d^{-1 / 2}
$$


The value of $K_{g}$ for similar nickel superalloys is estimated to be $750 \mathrm{MPa} \mu \mathrm{m}^{1 / 2}[35,66]$. This value does not account for annealing twins, which are likely to form in this alloy. While annealing twins do not affect the crystal structure itself, they do affect the stacking sequence, and it is suggested in some literature that this can hinder dislocations [40,71-75]. However, annealing twins only hinder dislocations when they dissociate into widely spaced Shockley partial dislocations, as the dislocation must recombine to pass through the twin boundary and move to a slip plane in a new orientation [71-74]. In the current material, the stacking fault energy, $\gamma$, is approximately $88 \mathrm{mJm}^{-2}$ (Equation (7), where the symbol for each element represents the content of that element in wt. \% [76]), which is significantly higher than those in which annealing twins have been found to block dislocations. It is likely that the dislocations do not split into partial dislocations and so twins will offer no barrier to dislocation motion. Therefore, it is unlikely that the twins play a significant strengthening role, and twins may be ignored when calculating grain refinement strengthening in the current alloy.

$$
\begin{gathered}
\gamma=1.59 \mathrm{Ni}-1.34 \mathrm{Mn}+0.06 \mathrm{Mn}^{2}-1.75 \mathrm{Cr}+0.01 \mathrm{Cr}^{2}+15.21 \mathrm{Mo}- \\
5.59 \mathrm{Si}-60.69(\mathrm{C}+1.2 \mathrm{~N})^{0.5}+26.27(\mathrm{C}+1.2 \mathrm{~N})(\mathrm{Cr}+\mathrm{Mn}+\mathrm{Mo})+ \\
0.61[\mathrm{Ni}(\mathrm{Cr}+\mathrm{Mn})]
\end{gathered}
$$

A modified expression for yield strength in an austenitic stainless steel has been published, and it takes into account both grain refinement and work hardening (Equation (8), where $\alpha_{\varepsilon}$ is a fitted constant that depends on the strength of the dislocation-dislocation interaction, and all other variables have the meanings expressed previously) [42].

$$
\sigma_{\mathrm{y}}=\sigma_{0}+K_{\mathrm{G}} d^{-1 / 2}+\alpha_{\varepsilon} M G b \rho^{1 / 2}
$$

The heat treatment at a temperature of $950{ }^{\circ} \mathrm{C}$ could lead to any, all or none of the static recrystallization, recovery and grain growth, depending on the state of the sample after forging. The large number of variables means that it is not feasible to calculate the grain size or dislocation density after stabilization in this study, but future studies could attempt such modeling.

\subsubsection{Precipitate Strengthening}

The volume fraction of non-matrix phases is predicted to be very small, even if full equilibrium is achieved (Figure 2). In the current case, a typical time, $t$, is given by the well-known estimation $t=x^{2} / D$, where $x$ is the diffusion distance, and $D$ is the relevant diffusivity. Taking values of the Burgers vector for the diffusion distance $\left(2.54 \times 10^{-8}\right) \mathrm{cm}$ and nickel self-diffusivity at the deformation temperature from the literature $\left.\left(6 \times 10^{-13} \mathrm{~cm}^{2} \mathrm{~s}^{-1}\right)[77,78]\right)$, the time required for one climb event is estimated to be $1 \mathrm{~ms}$. Given the rapid and prolonged deformation, it is unlikely that repeated climbs can accommodate the deformation, and so it is concluded that Orowan bowing is the limiting mechanism for the strengthening effect of precipitates in the current study.

The strengthening effect related to the Orowan bowing mechanism of dispersion hardening depends on the shear modulus of the matrix, $G$, the Burgers vector of the dislocations, $b$, and the mean spacing between precipitates, $L$ (Equation (9), where $M$ is the Taylor factor of approximately 3.1 and $\zeta$ is a constant $[30,63])$.

$$
\sigma_{\mathrm{b}}=\frac{\zeta M G b}{L}
$$

The value of $\zeta$ and the definition of $L$ vary between studies. $\zeta$ characterizes the interaction between dislocations and the precipitates and is sometimes reported as $1[30,63]$, and found to be either $0.8[28,30,79]$ or $1.5[35,80]$, based on dislocation theory.

There are various approaches for estimating the effective distance between particles in the glide plane, $L$. While studies agree that $L$ is the spacing between particles through 
which dislocations can pass, its definition is always approximate, and it may be defined by a simple expression for the linear mean free path $[81,82]$ (Equation (10)).

$$
L=\frac{4\left(1-f_{\mathrm{p}}\right) r_{\mathrm{p}}}{3 f_{\mathrm{p}}}
$$

where $r_{p}$ and $f_{p}$ are the mean particle radius and the volume fractions, respectively. Approximate values may be calculated from thermokinetic precipitation simulations in ThermoCalc Prisma (Figure 4).

Another approach asserts that the Orowan strengthening can be calculated by using the Bacon-Kocks-Scattergood equation (Equation (11), where $A \approx 0.2$ is a coefficient related to the type of dislocations [67-73], $\bar{D}$ is a harmonic average that describes the two limit cases of the Orowan strengthening (small, widely spaced particles and relatively large, closely spaced particles), and all other symbols have the meaning defined previously). The harmonic average is given by Equation (12), where $D_{\mathrm{p}}=2 r_{\mathrm{p}}$, and $L_{\mathrm{P}}=L+2 r_{\mathrm{p}}$ is the separation of the precipitate centers [81]. A comparison of Equations (9) and (11) show that $\zeta \equiv A\left[\ln \left(\frac{\bar{D}}{b}\right)+0.7\right]$, and is dependent on the precipitate population via $\bar{D}$ and the crystal structure of the matrix via $b$.

$$
\begin{gathered}
\sigma_{\mathrm{b}}=A \frac{M G b}{L_{\mathrm{p}}}\left[\ln \left(\frac{\bar{D}}{b}\right)+0.7\right] \\
\bar{D}=\frac{D_{\mathrm{p}} L_{\mathrm{P}}}{\left(D_{\mathrm{p}}+L_{\mathrm{P}}\right)}
\end{gathered}
$$

There is no physical basis on which any of the potential values of $\zeta$ may be selected, and so each will be examined to test the calculated value of the interfacial energy of the $\operatorname{Ti}(\mathrm{C}, \mathrm{N})$ precipitates to be derived. However, the plurality of evidence in the literature suggests that a value of $\zeta=0.8$ is the most likely candidate. Equation (9) will be used together with the particle radius of $39 \mathrm{~nm}$ and a precipitate fraction of 0.2 at. \% from the precipitation simulations (Figure 4), together with a precipitate spacing of $1.3 \mu \mathrm{m}$ (Equation (10)). The harmonic average spacing $\bar{D}=0.64 \mu \mathrm{m}$ (Equation (12)). Values of $\zeta=0.8,1.0$ and 1.5 are tested for completeness (Table 5). The strengthening contribution of precipitates is predicted to be between $37 \mathrm{MPa}$ and $116 \mathrm{MPa}$. The precipitate volume and size can also be measured directly from microscopic analysis of the microstructure $[83,84]$. This was not possible in the trials presented here but will be considered in future studies.

\begin{tabular}{|c|c|c|c|c|}
\hline Source & $\begin{array}{c}\text { Brown and } \\
\text { Ham }[28,30,79]\end{array}$ & $\begin{array}{c}\text { Orowan } \\
{[39,61]}\end{array}$ & $\begin{array}{c}\text { Goodfellow } \\
\text { [35] }\end{array}$ & $\begin{array}{c}\text { Bacon-Kocks } \\
\text { Scattergood } \\
{[85]}\end{array}$ \\
\hline$L / \mu \mathrm{m}$ & $\begin{array}{c}1.3 \\
\text { Equation (10) }\end{array}$ & $\begin{array}{c}1.3 \\
\text { Equation (10) }\end{array}$ & $\begin{array}{c}1.3 \\
\text { Equation (10) }\end{array}$ & $\begin{array}{c}0.64 \\
\text { Equation (12) }\end{array}$ \\
\hline$\zeta$ & 0.8 & 1.0 & 1.5 & 1.3 \\
\hline$\sigma_{b} / \mathrm{MPa}$ & $\begin{array}{c}37 \\
\text { Equation (9) }\end{array}$ & $\begin{array}{c}46 \\
\text { Equation (9) }\end{array}$ & $\begin{array}{c}69 \\
\text { Equation (9)) }\end{array}$ & $\begin{array}{c}116 \\
\text { Equation (11) }\end{array}$ \\
\hline
\end{tabular}

Table 5. Calculated Orowan bowing strengthening contributions using the various relationships found in the literature.

\subsubsection{Overall Prediction of Yield Strength}

By combining Equations (2), (3) and (8)-(10), it is possible to derive a general expression for the yield stress of an alloy similar to Alloy 825 (Equation (13), where $\sigma_{\mathrm{b}}$ can either be replaced according to the Orowan equation (Equations (9) and (10) or the Bacon-KocksScattergood approach (Equations (11) and (12)). This may be simplified for the current case by using the information presented in this section (Equation (14), where the value of $\sigma_{\mathrm{b}}$ has been set to $37 \mathrm{MPa}$, as the variation within the literature suggests that the Orowan equation 
with $\zeta=0.8$ is the most likely to be correct). The grain size, $d$, and the dislocation density may be measured, and so values may be derived for $K_{\mathrm{G}}$ and $\alpha_{\varepsilon}$ by solving simultaneous equations from a minimum of three experimental datasets, including yield strength, grain size and dislocation density. It will also be possible to compare the possible values for $\sigma_{\mathrm{b}}$ to see which is the most correct to use in the current case.

$$
\begin{gathered}
\sigma_{\mathrm{y}}=\sigma_{\mathrm{p}}+\left(1-f_{\mathrm{p}, \text { tot }}\right)\left(\sum_{i=1}^{i} \psi_{i}{ }^{2 / 3} x_{i}\right)^{3 / 2}+\sigma_{\mathrm{b}}+K_{\mathrm{G}} d^{-1 / 2}+\alpha_{\varepsilon} M G b \rho^{1 / 2} \\
\sigma_{\mathrm{y}} \approx 167 \mathrm{MPa}+K_{\mathrm{G}} d^{-1 / 2}+60 \alpha_{\varepsilon} \rho^{1 / 2}
\end{gathered}
$$

\section{Results}

\subsection{Microstructural Evolution}

The averages of grain sizes in the as-stabilized samples are summarized in Table 6. The stabilized microstructures that developed in the material subjected to hot-forging and subsequent annealing are shown in Figure 5. Figure 5a-d show that an annealing (stabilization) temperature of $950{ }^{\circ} \mathrm{C}$ does not lead to significant changes in the forged microstructures, suggesting that static recovery is the main process that removes dislocations at this temperature. It can be clearly seen (Figure 5a-d) that the texture in the stabilized samples is random. KAM measurements from EBSD data allow the dislocation density in each sample to be derived (Equation (1), Table 7).

Table 6. Mean grain size in as-stabilized samples, including the standard deviation of the measurements.

\begin{tabular}{cccc}
\hline Sample & A & B & C \\
\hline$d / \mu \mathrm{m}$ & $66 \pm 8$ & $53 \pm 7$ & $36 \pm 3$ \\
\hline
\end{tabular}

Table 7. Dislocation density, $\rho$, calculated using Equation (1). Values of $\theta$ were measured during EBSD of the as-stabilized material, and $s$ is the step size of the EBSD scan.

\begin{tabular}{ccc}
\hline Sample & $\frac{\theta}{s} / \mathbf{m}^{-1}$ & $\rho / \mathbf{m}^{-2}$ \\
\hline A & $3.90 \times 10^{3}$ & $3.06 \times 10^{13}$ \\
B & $7.62 \times 10^{3}$ & $6.01 \times 10^{13}$ \\
C & $1.11 \times 10^{4}$ & $8.71 \times 10^{13}$ \\
\hline
\end{tabular}

\subsection{Mechanical Properties of As-Stabilized Material}

The tensile tests reveal that all samples exhibited significant work hardening and ductility during deformation, and had a yield stress and ultimate tensile strength that exceed the requirements of the relevant industrial standard, [1] (Table 8, Figure 6). For the purposes of this study, $0.2 \%$ proof stress is taken to be acceptable as a measure of yield stress. 


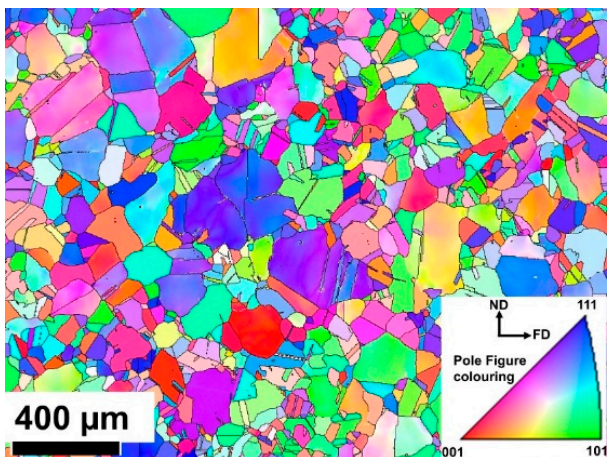

(a)

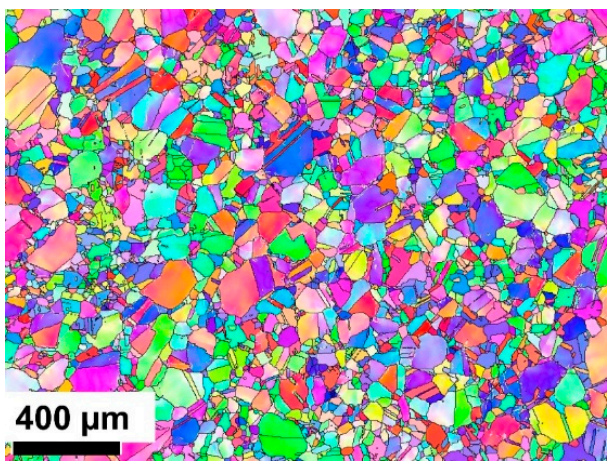

(c)

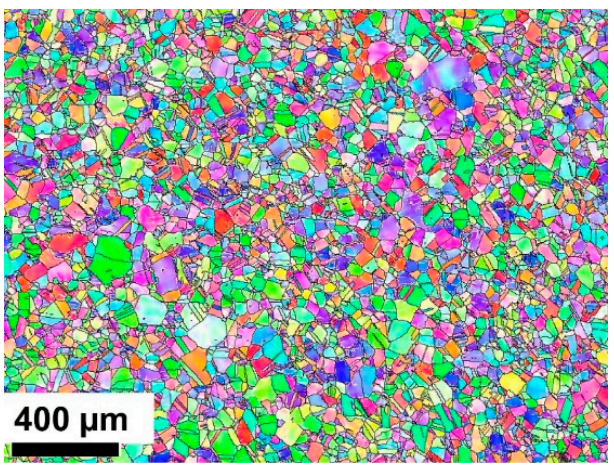

(e)

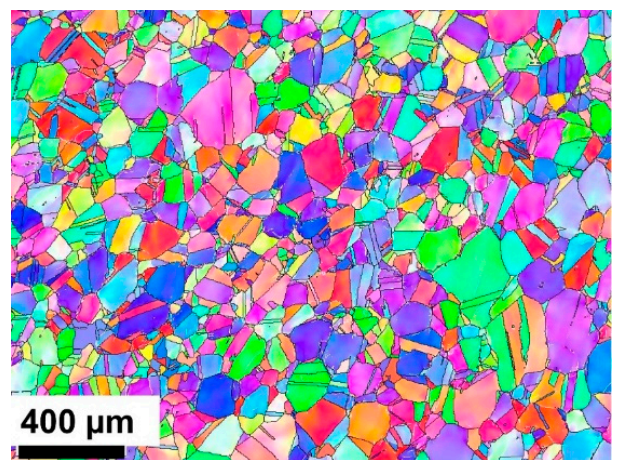

(b)

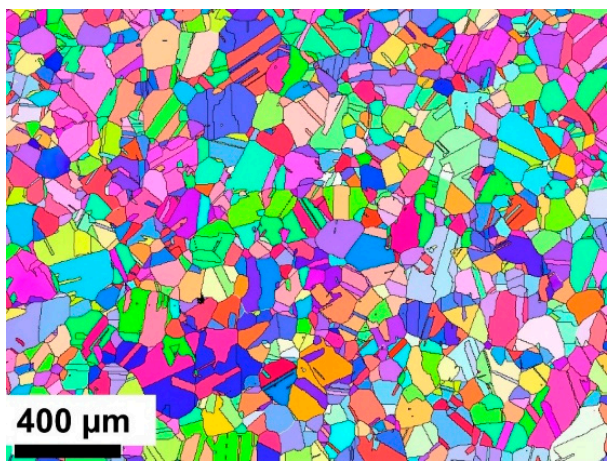

(d)

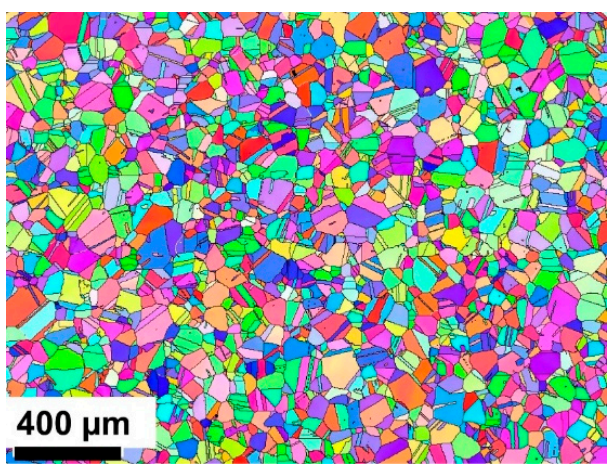

(f)

Figure 5. Inverse pole figure maps measured using EBSD showing the distribution of crystallographic directions oriented parallel to the forging axis after forging $(\mathbf{a}, \mathbf{c}, \mathbf{e})$ and stabilization $(\mathbf{b}, \mathbf{d}, \mathbf{f})$ in $(\mathbf{a}, \mathbf{b})$ sample A, (c,d) sample B, and (e,f) sample C. Typical microstructures in Alloy 825 subjected to hot-forging at different strain levels and subsequent annealing for $1 \mathrm{~min}$ per millimeter of rod radius at $950{ }^{\circ} \mathrm{C}$.

Table 8. The room temperature mechanical properties of as-stabilized samples, together with the minimum mechanical property requirements according to the relevant industry standard [1].

\begin{tabular}{ccccc}
\hline Sample & $\begin{array}{c}\mathbf{0 . 2 \%} \text { Proof } \\
\text { Stress/MPa }\end{array}$ & $\begin{array}{c}\text { Ultimate Tensile } \\
\text { Strength/MPa }\end{array}$ & $\begin{array}{c}\text { Failure Strain, } \\
\boldsymbol{\varepsilon}_{\mathbf{f}} \mathbf{( \% )}\end{array}$ & $\begin{array}{c}\text { Reduction of } \\
\text { Area, } \boldsymbol{A}_{\mathbf{r}} \mathbf{( \% )}\end{array}$ \\
\hline $\begin{array}{c}\text { Specified } \\
\text { minimum [1] }\end{array}$ & 241 & 586 & 30 & - \\
A & $284 \pm 3.5$ & $589 \pm 2.2$ & $47 \pm 4.2$ & $68 \pm 2.1$ \\
B & $319 \pm 7.0$ & $613 \pm 4.0$ & $43 \pm 3.6$ & $66 \pm 0.6$ \\
C & $348 \pm 3.5$ & $618 \pm 6.7$ & $40 \pm 1.5$ & $67 \pm 4.6$ \\
\hline
\end{tabular}




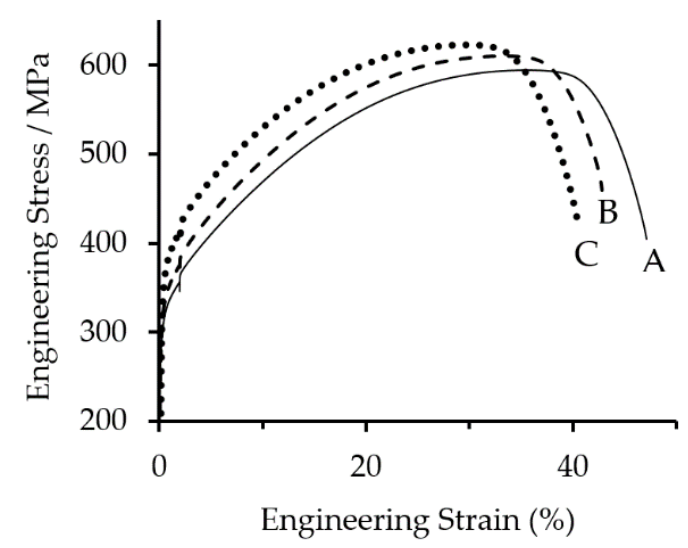

Figure 6. Engineering stress-strain curves for room-temperature tensile testing of the stabilized samples indicated. Each curve is labelled with the sample designation (Table 2).

\section{Discussion}

\subsection{Microstructure of As-Stabilized Samples}

The observed microstructure after stabilization is consistent with the results of thermodynamic modeling (Figure 4). The material is found to consist of a face-centered cubic matrix containing titanium carbonitrides and precipitates rich in chromium and molybdenum, which is consistent with the chemistry of the phase, designated "SIGMA" in the thermodynamic calculation results (Figure 2). These findings are also consistent with other published studies for similar materials [11,86-88]. Furthermore, many annealing twins can also be seen in the annealed microstructure, which is also consistent with published studies of similar alloys. Scanning electron microscopy of as-stabilized sample $\mathrm{C}$ reveals precipitates rich in chromium and molybdenum (marked with open circle), with an average size of $600 \mathrm{~nm}$ at some grain boundaries (Figure $7 \mathrm{a}, \mathrm{b}$ ). These precipitates were not found in the initial or as-forged conditions. Furthermore, EDS of the sample indicates that the precipitates are enriched in molybdenum and carbon but depleted in chromium. Similar Cr-Mo-rich precipitates have been reported in the Incoloy 825 nickel-base superalloy in both unaged and aged conditions [88].

These precipitates are not predicted to form, based on the results of thermodynamic modeling, but are consistent with the "SIGMA" phase that is predicted and could have formed during heating before or cooling after the stabilization treatment. However, the volume fraction of such precipitates is very low, and it is unlikely that the mechanical properties of the material are affected by such precipitates to a significant extent.

All other observations are as expected from the results of thermodynamic modeling. However, the presence of any grain boundary precipitates means that it is likely to be very difficult to predict grain growth during the soft annealing treatment, and so no attempt has been made to do so in the current study. This is supported by the difference in behavior between the three samples during soft annealing. Sample A saw grain growth, sample $B$ saw no significant change in grain size and the grains in sample $C$ became smaller on average. This behavior is probably due to the different dislocation densities in the samples: sample $C$, which underwent the most forging strain, is likely to have contained the highest dislocation density, and so recrystallization was possible during stabilization. Conversely, sample A contained the lowest dislocation density and so did not recrystallize to the same extent (if at all) during stabilization, and grain growth was the only phenomenon affecting the grain size. It was also observed that almost all grains in sample A had undergone recrystallization during forging, compared to only $36 \%$ of grains in sample C. The remaining grains were classified as deformed and contained high dislocation densities, which could drive recrystallization. 

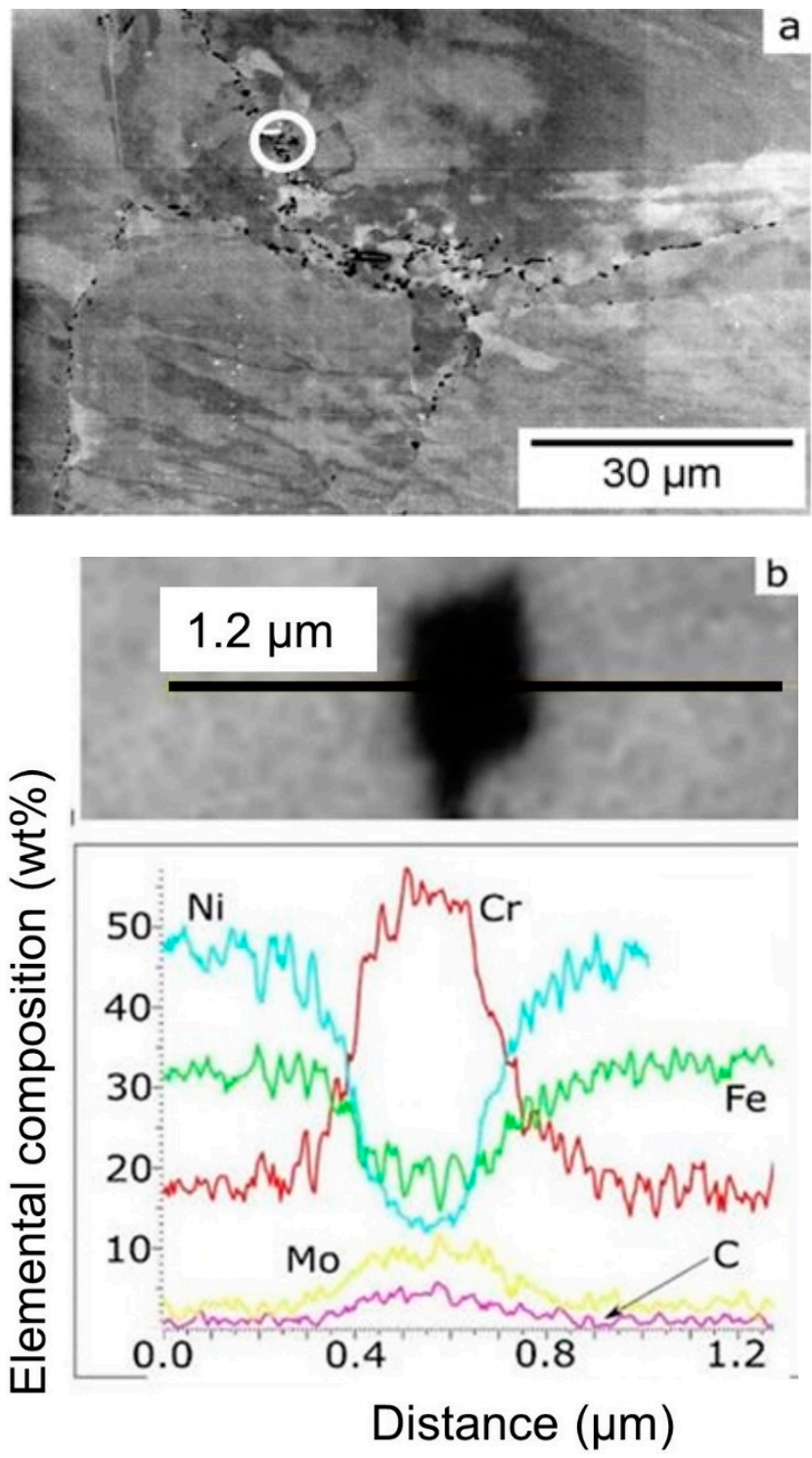

Figure 7. (a) SEM image of the as-stabilized microstructure of sample C (b) SEM image and EDS line scan data acquisition across the precipitate indicated. Examples of precipitates rich in chromium, molybdenum and iron are highlighted by the open circle.

\subsection{Mechanical Properties of As-Stabilized Material}

\subsubsection{Grain Refinement and Work Hardening}

The relationship between the yield strength, grain size and dislocation density (Equation (8)) can be used to derive the unknown parameters $K_{\mathrm{G}}, \alpha_{\varepsilon}$ and $\sigma_{0}$. Combining the yield strengths, dislocation densities and grain sizes (Table 9), and using Gaussian elimination, gives the values of each quantity as $0.21 \mathrm{MPa} \mathrm{m} \mathrm{m}^{0.5}, 0.24$, and $178 \mathrm{MPa}$, respectively. The value of $K_{\mathrm{G}}$ is of the same magnitude of similar materials reported in the literature [42,89-92], and so it is a reasonable result. The value of $\alpha_{\varepsilon}$ is lower than the published results for work-hardened austenitic stainless steels $(\sim 0.3)[91,93,94]$. The plot of yield strength values calculated using Equation (14) against experimental results on yield stress, $\sigma_{\mathrm{y}}$, is found to be linear. The correlation coefficient $\left(R^{2}\right)$ is 0.99 , suggesting that the relationship is reliable. 
Table 9. Parameters used to derive the modified Hall-Petch parameter, $K_{\mathrm{G}}$, work hardening parameter, $\alpha_{\varepsilon}$, and intrinsic strength, $\sigma_{0}$.

\begin{tabular}{cccc}
\hline Sample & $\sigma_{\mathbf{y}} / \mathbf{M P a}$ & $d / \mu \mathrm{m}$ & $\rho / \mathbf{m}^{-2}$ \\
\hline A & 284 & 66 & $3.06 \times 10^{13}$ \\
B & 319 & 53 & $6.01 \times 10^{13}$ \\
C & 348 & 36 & $8.71 \times 10^{13}$ \\
\hline
\end{tabular}

This is consistent with materials subjected to a soft annealing treatment, in which dislocations interact more weakly than in work-hardened materials, where internal stress fields caused by the accumulated dislocations provide an additional barrier to the motion of other dislocations [56]. The value of $\sigma_{0}$ is consistent with the strengthening mechanisms that contribute to it (Peierls stress of $3 \mathrm{MPa}$, solid solution strengthening of $127 \mathrm{MPa}$ and precipitate strengthening of between $36 \mathrm{MPa}$ and $116 \mathrm{MPa}$ ).

\subsubsection{Precipitation Strengthening}

By considering Equations (2) and (8), subtracting the effects of the contributions of grain refinement and work hardening, the sum of the contributions of the Peierls stress, solid solution strengthening and precipitation strengthening must be equal to $\sigma_{0}=\sigma_{\mathrm{p}}+\sigma_{\mathrm{s}}$ $+\sigma_{\mathrm{b}}=178 \mathrm{MPa}$. Based on the known contributions of the Peierls stress ( $3 \mathrm{MPa}$ ) and solid solution strengthening $(127 \mathrm{MPa})$, the contribution of precipitation strengthening, $\sigma_{\mathrm{b}}$, must be $48 \mathrm{MPa}$. This implies that the Orowan equation with a coefficient $\zeta=1.0$ (predicted strengthening effect of $46 \mathrm{MPa}$ ) is the appropriate equation to use to describe precipitate strengthening. Further investigations are required to confirm if this is a consistent result for this and similar alloys and heat treatments, or if another of the proposed relationships is a better predictor. This knowledge will allow the strength of Alloy 825 to be predicted as a function of microstructural features and composition, all of which can be measured with a scanning electron microscope.

\section{Conclusions}

Tensile test data have been used, together with theory, to assess the contribution of the various strengthening mechanisms in nickel-base Alloy 825 after hot-forging and annealing. The main conclusions of this study are:

- Solid solution strengthening is very significant in the current alloy, contributing $127 \mathrm{MPa}$ to the yield strength.

- The strengthening was attributed to both the fine static recrystallized grain and the high dislocation density, which were developed by the forging strain levels and subNot applicable.sequent soft annealing. The yield strength, $\sigma_{\mathrm{y}}$, could be expressed through the static recrystallized grain size, $d$, and the dislocation density, $\rho$, by a modified Hall-Petch-type relationship,

$$
\sigma_{\mathrm{y}} \approx 178 \mathrm{MPa}+0.213 d^{-1 / 2}+0.24 G b \rho^{1 / 2}
$$

where $G$ is the shear modulus and $b$ is Burgers vector. The relationship between calculated and experimental yield strength values is linear with less than $1 \%$ disagreement. The regression coefficient, $R^{2}$, for the relationship is 0.99 ;

- Precipitation strengthening in the current alloy was found to be $48 \mathrm{MPa}$ after the thermomechanical treatment and can be predicted with high accuracy ( $46 \mathrm{MPa}, 4 \%$ difference) using the conventional Orowan equation;

- A higher forging strain leads to higher yield strength after soft annealing (stabilization). This was attributed to greater recrystallization, which led to increased grain refinement and grain size strengthening. The highest as-annealed yield strength measured was $348 \mathrm{MPa}$, and the highest ultimate tensile strength was $618 \mathrm{MPa}$, both of which occurred in the sample deformed to the largest total strain. All samples showed good 
ductility (40\%). All annealed samples met the requirements of the relevant industry standard [1];

- The interfacial energy of $\mathrm{Ti}(\mathrm{C}, \mathrm{N})$ in the face-centered cubic matrix of the current alloy is $0.8 \mathrm{~mJ} \mathrm{~m}^{-2}$, derived by simulating the precipitation and growth of $\operatorname{Ti}(\mathrm{C}, \mathrm{N})$ during the soft annealing treatment to match the growth to experimental observations. To the knowledge of the authors, this is the first time that this energy has been quantified.

Author Contributions: Conceptualization, M.A.-S., F.S. and P.G.J.; methodology, M.A.-S. and C.N.H.S.; validation, M.A.-S.; formal analysis, M.A.-S. and C.N.H.-S.; investigation, M.A.-S.; resources, P.G.J. and F.S.; writing —original draft preparation, M.A.-S.; writing—review and editing, C.N.H.-S. and P.G.J.; visualization, M.A.-S.; supervision, C.N.H.-S., P.G.J. and F.S.; project administration, C.N.H.-S., P.G.J. and F.S. All authors have read and agreed to the published version of the manuscript.

Funding: This research received no external funding.

Institutional Review Board Statement: Not applicable.

Informed Consent Statement: Not applicable.

Data Availability Statement: The data presented in this study are available on request from the corresponding author. The data are not publicly available due to potential commercial sensitivity.

Acknowledgments: Munir Al-Saadi would like to thank Sandvik Materials Technology for the financial support, and the permission to publish this paper.

Conflicts of Interest: The authors declare no conflict of interest.

\section{References}

1. ASTM. B425-11 Standard Specification for Ni-Fe-Cr-Mo-Cu Alloy (UNS N08825 and UNS N08221) Rod and Bar; ASTM International: West Conshohocken, PA, USA, 2011.

2. ASTM. B564-15 Standard Specification for Nickel Alloy Forgings; ASTM International: West Conshohocken, PA, USA, 2015.

3. ASTM. B423-11 Standard Specification for Nickel-Iron-Chromium-Molybdenum-Copper Alloy (UNS N08825 and N08221)* Seamless Pipe and Tube; ASTM International: West Conshohocken, PA, USA, 2011.

4. Hodge, F.G. The History of Solid-Solution-Strengthened Ni Alloys for Aqueous Corrosion Service. JOM 2006, 58, 28-31. [CrossRef]

5. Botinha, J.; Krämer, J.; Genchev, G.; Bosch, C.; Alves, H. Effect of Sensitization on the Corrosion Resistance of an Advanced Version of Alloy UNS N08825. In Proceedings of the NACE International Corrosion Conference, Nashville, TN, USA, 24-28 March 2019; pp. 1-12.

6. Tassen, C.S.; Smith, G.D.; Mannan, S.K.; Hinshaw, E.B. Fabrication, Welding and Heat Treatment of Nickel Alloys UNS N08800, N08810, N0881, and N08825. In Proceedings of the Paper No. 601, NACE-Corrosion 96; NACE International: Houston, TX, USA, 1996; pp. 1-10.

7. Helena, A. Nickel alloys and high alloyed stainless steels for heat exchangers and other applications in chlorinated seawater. In Proceedings of the Corrosion Conference and Expo, Nashville, TX, USA, 11-15 March 2007; Volume 59, pp. 1-20.

8. Shoemaker, L.; Crum, J. Processing and fabricating alloy 825 for optimized properties and corrosion resistance. In Proceedings of the NACE Corrosion Conference, Houston, TX, USA, 13-17 March 2011; pp. 1-13.

9. SpecialMetals INCOLOY ${ }^{\circledR}$ Alloy 825. Available online: http://www.specialmetals.com (accessed on 11 March 2021).

10. Mankins, W.L.; Lamb, S. Nickel and Nickel Alloys. In ASM Metals Handbook Volume 2, Properties and Selection: Nonferrous Alloys and Special-Purpose Materials; ASM International: Materials Park, OH, USA, 1990; pp. 428-445.

11. Raymond, E.L. Mechanisms of Sensitization and Stablization of Incoloy Nickel-lron-Chromium Alloy 825. CORROSION 1968, 24, 180-188. [CrossRef]

12. Gustafson, Å. Coarsening of TiC in austenitic stainless steel-Experiments and simulations in comparison. Mater. Sci. Eng. A 2000, 287, 52-58. [CrossRef]

13. Datasheet. Sanicro ${ }^{\circledR} 825$ Bar; AB Sandvik Materials Technology: Sandviken, Sweden, 2021.

14. Yu, M.; Li, J.; Tang, H.; Bao, Y. Hot Working Characteristics of Corrosion-Resistant Alloys G3 and 825. J. Iron Steel Res. Int. 2011, 18, 68-72. [CrossRef]

15. Al-Saadi, M.; Sandberg, F.; Kasarav, A.; Jonsson, S.; Jönsson, P. Microstructure characterisation in alloy 825. Procedia Manuf. 2018, 15, 1626-1634. [CrossRef]

16. Al-Saadi, M.; Sandberg, F.; Hulme-Smith, C.; Karasev, A.; Jönsson, P.G. A study of the static recrystallization behaviour of cast Alloy 825 after hot-compressions. J. Phys. Conf. Ser. 2019, 1270, 012023. [CrossRef]

17. Yang, L.; Geng, Z.; Zhang, M.; Dong, J. Study on hot deformation behavior and numerical simulation for hot extrusion process of corrosion resistant 825 alloy. Procedia Eng. 2012, 27, 997-1007. [CrossRef] 
18. Basirat, M. Plastic Deformation and Recrystallization in Incoloy 825. Ph.D. Thesis, KTH Royal Institute of Technology, Stockholm, Sweden, 2013.

19. Niikura, M.; Takahashi, K.; Ouchi, C. Microstructural change of austenite in hot working with a very high reduction. Trans. Iron Steel Inst. Japan 1987, 27, 485-491. [CrossRef]

20. Sandström, R.; Lagneborg, R. A controlling factor for dynamic recrystallisation. Scr. Metall. 1975, 9, 59-65. [CrossRef]

21. Sellars, C.M.; Tegart, W.J.M. Hot workability. Inter. Met. Rev. 1972, 17, 1-24. [CrossRef]

22. Jonas, J.J.; Sellars, C.M.; Tegart, W.J.M. Strength and structure under hot-working conditions. Metall. Rev. 1969, 14, 1-24. [CrossRef]

23. Sakai, T.; Belyakov, A.; Kaibyshev, R.; Miura, H.; Jonas, J.J. Dynamic and post-dynamic recrystallization under hot, cold and severe plastic deformation conditions. Prog. Mater. Sci. 2014, 60, 130-207. [CrossRef]

24. Roth, H.A.; Davis, C.L.; Thomson, R.C. Modeling solid solution strengthening in nickel alloys. Metall. Mater. Trans. A Phys. Metall. Mater. Sci. 1997, 28, 1329-1335. [CrossRef]

25. Gypen, L.A.; Deruyttere, A. Multi-component solid solution hardening_Part 1 Proposed model. J. Mater. Sci. 1977, 12, 1028-1033. [CrossRef]

26. Smola, B. Precipitation and Hardening Mechanisms in the AISI 321 Steel. Acta Univ. Carolinae-Math. Phys. 1990, $31,27-46$.

27. Gypen, L.A.; Deruyttere, A. Multi-component solid solution hardening-Part 2 Agreement with experimental results. J. Mater. Sci. 1977, 12, 1034-1038. [CrossRef]

28. Gladman, T. Precipitation hardening in metals. Mater. Sci. Technol. 1999, 15, 30-36. [CrossRef]

29. Lagneborg, R. Bypassing of dislocations past particles by a climb mechanism. Scr. Metall. 1973, 7, 605-613. [CrossRef]

30. Brown, L.M.; Ham, R.K. Dislocation-particle interactions. In Strengthening Methods in Crystals; Kelly, A., Nicholson, R.B., Eds.; Applied Science Publishers LTD: London, UK, 1971; pp. 9-135.

31. Ardell, A.J. Precipitation hardening. Metall. Trans. A 1985, 16, 2131-2165. [CrossRef]

32. Tien, J.K.; Jacobs, E.G. Oxide Dispersion Strengthened Alloys; Academic Press, INC: Cambridge, MA, USA, 2012.

33. Nooning, R.G., Jr. Effect of Stabilizing Elements on the Precipitation Behavior and Phase Stability of Type 409 Ferritic Stainless Steels. Master's Thesis, University of Pittsburgh, Pittsburgh, PA, USA, 2002.

34. Al-Saadi, M. Optimization of Foprged Alloy 825 Production Conditions. Licentiate Thesis, KTH Royal Institute of Technology, Stockholm, Sweden, 2019.

35. Goodfellow, A.J.; Galindo-Nava, E.I.; Schwalbe, C.; Stone, H.J. The role of composition on the extent of individual strengthening mechanisms in polycrystalline Ni-based superalloys. Mater. Des. 2019, 173, 107760. [CrossRef]

36. Hall, O.E. The deformation and ageing of mild steel: II Characterisitics of the Luders deformation. Proc. Phys. Soc. Sect. B 1951, 64, 742. [CrossRef]

37. Armstrong, R.; Codd, I.; Douthwaite, R.M.; Petch, N.J. The plastic deformation of polycrystalline aggregates. Philos. Mag. A J. Theor. Exp. Appl. Phys. 1962, 7, 45-58. [CrossRef]

38. Hall, E.O. The deformation and ageing of mild steel: III Discussion of results. Proc. Phys. Soc. Sect. B 1951, 64, 747-753. [CrossRef]

39. Cracknell, A.; Petch, N.J. Frictional forces on dislocation. Acta Metall. 1955, 3, 186-189. [CrossRef]

40. Schneider, M.; George, E.P.; Manescau, T.J.; Záležák, T.; Hunfeld, J.; Dlouhý, A.; Eggeler, G.; Laplanche, G. Analysis of strengthening due to grain boundaries and annealing twin boundaries in the CrCoNi medium-entropy alloy. Int. J. Plast. 2020, 124, 155-169. [CrossRef]

41. Armstrong, R.W. The (cleavage) strength of pre-cracked polycrystals. Eng. Fract. Mech. 1987, 28, 529-538. [CrossRef]

42. Mecking, H.; Kocks, U.F. Kinetics of flow and strain-hardening. Acta Metall. 1981, 29, 1865-1875. [CrossRef]

43. Raveendra, S.; Mishra, S.; Krishna, K.V.M.; Weiland, H.; Samajdar, I. Patterns of Recrystallization in Warm- and Hot-Deformed. Metall. Mater. Trans. A 2008, 39A, 2760-2771. [CrossRef]

44. ASTM. E2627-13 (Reapproved 2019) Standard Practice for Determining Average Grain Size Using Electron Backscatter Diffraction (EBSD) in Fully Recrystallized Polycrystalline Materials; ASTM International: West Conshohocken, PA, USA, 2013.

45. ASTM. E112-2012 Standard Test Methods for Determining Average Grain Size; ASTM International: West Conshohocken, PA, USA, 2012.

46. Field, D.P.; Bradford, L.T.; Nowell, M.M.; Lillo, T.M. The role of annealing twins during recrystallization of Cu. Acta Mater. 2007, 55, 4233-4241. [CrossRef]

47. Ayad, A.; Allain-Bonasso, N.; Rouag, N.; Wagner, F. Grain Orientation Spread Values in if Steels after Plastic Deformation and Recrystallization. Mater. Sci. Forum 2011, 702-703, 269-272. [CrossRef]

48. Nordström, J.; Siriki, R.; Calmunger, M.; Moverare, J.; Chai, G. TWIP and Fracture Behavior in the Superalloy 625 at Room and Cryogenic Temperatures. Procedia Struct. Integr. 2019, 23, 457-462. [CrossRef]

49. Raveendra, S. Cube Stability in Aluminum. Ph.D. Thesis, Indian Institute of Technology, Bombay, India, 2010.

50. Seol, J.B.; Bae, J.W.; Li, Z.; Chan Han, J.; Kim, J.G.; Raabe, D.; Kim, H.S. Boron doped ultrastrong and ductile high-entropy alloys. Acta Mater. 2018, 151, 366-376. [CrossRef]

51. Zhilyaev, A.P.; Shakhova, I.; Morozova, A.; Belyakov, A.; Kaibyshev, R. Grain refinement kinetics and strengthening mechanisms in Cu-0.3Cr-0.5Zr alloy subjected to intense plastic deformation. Mater. Sci. Eng. A 2016, 654, 131-142. [CrossRef]

52. Zhilyaev, A.P.; Shakhova, I.; Belyakov, A.; Kaibyshev, R.; Langdon, T.G. Wear resistance and electroconductivity in copper processed by severe plastic deformation. Wear 2013, 305, 89-99. [CrossRef] 
53. Liu, Q.; Juul Jensen, D.; Hansen, N. Effect of grain orientation on deformation structure in cold-rolled polycrystalline aluminium. Acta Mater. 1998, 46, 5819-5838. [CrossRef]

54. Kubin, L.P.; Mortensen, A. Geometrically necessary dislocations and strain-gradient plasticity: A few critical issues. Scr. Mater. 2003, 48, 119-125. [CrossRef]

55. Calcagnotto, M.; Ponge, D.; Demir, E.; Raabe, D. Orientation gradients and geometrically necessary dislocations in ultrafine grained dual-phase steels studied by 2D and 3D EBSD. Mater. Sci. Eng. A 2010, 527, 2738-2746. [CrossRef]

56. Odnobokova, M.; Yanushkevich, Z.; Kaibyshev, R.; Belyakov, A. On the Strength of a 316L-Type Stainless Steel Subjected to Cold or Warm Rolling Followed by Annealing. Materials 2020, 13, 2116. [CrossRef]

57. Liu, T.; Chen, D.; Long, M.; Liu, P.; Duan, H.; Gui, L.; Fan, H.; Chen, H. Control of Coarse Precipitates of Titanium Nitride in High-Strength Low-Alloy Steel. Met. Sci. Heat Treat. 2020, 61, 534-542. [CrossRef]

58. Adderley, P.; Hart, V.; Rosenberg, J.; Klöwer, J. Development of an Improved Version of UNS N08825 with Higher Corrosion Resistance. In Proceedings of the NACE Corrosion Conference, Vancouver, BC, Canada, 6-10 March 2016.

59. Thermo-Calc Software TCNI9/Ni-Alloys and Superalloy Solutions Database Version 9.1. Available online: https://thermocalc. com/support/how-to-cite-thermo-calc-products / (accessed on 15 December 2019).

60. Thermo-Calc Software TCNI9/MOBNI5-Ni-Alloys Mobility Database Version 5.1. Available online: https://thermocalc.com/ support/how-to-cite-thermo-calc-products/ (accessed on 15 December 2019).

61. Lin, J.; Zhu, T.; Zhan, L. Constitutive Equations for Modelling Superplastic Forming of Metals; Woodhead Publishing Limited: Cambridge, UK, 2011; ISBN 9781845697532.

62. Engberg, G.; Lissel, L. A Physically based Microstructure Model for Predicting the Microstructural Evolution of a C-Mn Steel during and after Hot Deformation. Steel Res. Int. 2008, 79, 47-58. [CrossRef]

63. Kozar, R.W.; Suzuki, A.; Milligan, W.W.; Schirra, J.J.; Savage, M.F.; Pollock, T.M. Strengthening Mechanisms in Polycrystalline Multimodal Nickel-Base Superalloys. Metall. Mater. Trans. A 2009, 40, 1588-1603. [CrossRef]

64. Taylor, G.; Vitek, V. Comment on "Glide systems and Peierls stresses in fcc and bcc metals from phonon energies". J. Appl. Phys. 1974, 45, 3218-3219. [CrossRef]

65. Walbrühl, M.; Linder, D.; Ågren, J.; Borgenstam, A. Modelling of solid solution strengthening in multicomponent alloys. Mater. Sci. Eng. A 2017, 700, 301-311. [CrossRef]

66. Galindo-Nava, E.I.; Connor, L.D.; Rae, C.M.F. On the prediction of the yield stress of unimodal and multimodal $\gamma^{\prime}$ Nickel-base superalloys. Acta Mater. 2015, 98, 377-390. [CrossRef]

67. Galindo-Nava, E.I.; Sietsma, J.; Rivera-Díaz-del-Castillo, P.E.J. Dislocation annihilation in plastic deformation: II. Kocks-Mecking Analysis. Acta Mater. 2012, 60, 2615-2624. [CrossRef]

68. Verlinden, B.; Driver, J.; Samajdar, I.; Doherty, R. Thermo-Mechanical Processing of Metallic Materials; Elsevier: Amsterdam, The Netherlands, 2007; Volume 11, ISBN 9780080444970.

69. Yanushkevich, Z.; Lugovskaya, A.; Belyakov, A.; Kaibyshev, R. Deformation microstructures and tensile properties of an austenitic stainless steel subjected to multiple warm rolling. Mater. Sci. Eng. A 2016, 667, 279-285. [CrossRef]

70. Schuh, C.A.; Nieh, T.G. Hardness and Abrasion Resistance of Nanocrystalline Nickel Alloys Near the Hall-Petch Breakdown Regime. MRS Proc. 2002, 740, 1-6. [CrossRef]

71. Priester, L.; Couzinié, J.P.; Décamps, B. Interaction between dislocations and grain boundaries role in plastic deformation. Adv. Eng. Mater. 2010, 12, 1037-1040. [CrossRef]

72. Couzinié, J.P.; Décamps, B.; Boulanger, L.; Priester, L. In-situ transmission electron microscopy study of glissile grain boundary dislocation relaxation in a near $\Sigma=3\{111\}$ grain boundary in copper. Mater. Sci. Eng. A 2005, 400-401, 264-267. [CrossRef]

73. Couzinié, J.P.; Decamps, B.; Priester, L. On the interactions between dislocations and a near- $\Sigma=3$ grain boundary in a low stacking-fault energy metal. Philos. Mag. Lett. 2003, 83, 721-731. [CrossRef]

74. Couzinié, J.P.; Décamps, B.; Priester, L. Interaction of dissociated lattice dislocations with a $\sum=3$ grain boundary in copper. Int. J. Plast. 2005, 21, 759-775. [CrossRef]

75. Pande, C.S.; Rath, B.B.; Imam, M.A. Effect of annealing twins on Hall-Petch relation inpolycrystalline materials. Mater. Sci. Eng. A 2004, 367, 171-175. [CrossRef]

76. Nordström, J.; Siriki, R.; Moverare, J.; Chai, G. Deformation Twinning Behavior in High Ni-Austenitic Materials. Mater. Sci. Forum 2018, 941, 1591-1596. [CrossRef]

77. Reynolds, J.E.; Averbach, B.L.; Cohen, M. Self-diffusion and interdiffusion in gold-nickel alloys. Acta Metall. 1957, 5, 29-40. [CrossRef]

78. Hirano, K.; Cohen, M.; Averbach, B.L. Diffusion of nickel into iron. Acta Metall. 1961, 9, 440-445. [CrossRef]

79. Gladman, T. The Physical Metallurgy of Microalloyed Steels; Institute of Materials: London, UK, 1997.

80. Reppich, B. Some new aspects concerning particle hardening mechanisms in $\gamma^{\prime}$ precipitating Ni-base alloys-I. Theoretical concept. Acta Metall. 1982, 30, 87-94. [CrossRef]

81. Corti, C.W.; Cotterill, P.; Fitzpatrick, G.A. The Evaluation of the Interparticle Spacing in Dispersion Alloys. Int. Metall. Rev. 1974, 19,77-88. [CrossRef]

82. Dieter, G.E. Mechanical Metallurgy, 3rd ed.; Sajeev Rao, Ed.; McGraw-Hill Science/Engineering/Math: New York, NY, USA, 1986; ISBN 0-07-016893-8. 
83. Zieliński, A.; Miczka, M.; Sroka, M. The effect of temperature on the changes of precipitates in low-alloy steel. Mater. Sci. Technol. 2016, 32, 1899-1910. [CrossRef]

84. Zieliński, A.; Miczka, M.; Golański, G. Forecasting the distribution of precipitate diameters in the presence of changes in the structure of the material. Arch. Metall. Mater. 2017, 62, 273-280. [CrossRef]

85. Bacon, D.J.; Kocks, U.F.; Scattergood, R.O. The effect of dislocation self-interaction on the orowan stress. Philos. Mag. 1973, 28, 1241-1263. [CrossRef]

86. Busch, J.D.; Debarbadillo, J.J.; Krane, M.J.M. Flux Entrapment and Titanium Nitride Defects in Electroslag Remelting of INCOLOY Alloys 800 and 825. Metall. Mater. Trans. A 2013, 44, 5295-5303. [CrossRef]

87. Pan, Y.-M.; Dunn, D.S.; Cragnolino, G.A.; Sridhar, N. Grain-boundary chemistry and intergranular corrosion in alloy 825. Metall. Mater. Trans. A 2000, 31, 1163-1173. [CrossRef]

88. Shaikh, M.A.; Iqbal, M.; Ahmad, M.; Akhtar, J.I.; Shoaib, K.A. Precipitation study of heat-treated Incoloy 825 by scanning electron microscopy. J. Mater. Sci. Lett. 1992, 11, 1009-1011. [CrossRef]

89. Matsuoka, Y.; Iwasaki, T.; Nakada, N.; Tsuchiyama, T. Effect of Grain Size on Thermal and Mechanical Stability of Austenite in Metastable Austenitic Stainless Steel. ISIJ Int. 2013, 53, 1224-1230. [CrossRef]

90. Rajasekhara, S.; Ferreira, P.J.; Karjalainen, L.P.; Kyro, A.; Society, M. On the significance of nature of strain-induced martensite on phase-reversion-induced nanograined/ultrafine-grained austenitic stainless steel. Metall. Mater. Trans. A 2007, 41, 3-12.

91. Yanushkevich, Z.; Belyakov, A.; Kaibyshev, R.; Haase, C.; Molodov, D.A. Effect of cold rolling on recrystallization and tensile behavior of a high-Mn steel. Mater. Charact. 2016, 112, 180-187. [CrossRef]

92. Hansen, N. Hall-petch relation and boundary strengthening. Scr. Mater. 2004, 51, 801-806. [CrossRef]

93. Yanushkevich, Z.; Mogucheva, A.; Tikhonova, M.; Belyakov, A.; Kaibyshev, R. Structural strengthening of an austenitic stainless steel subjected to warm-to-hot working. Mater. Charact. 2011, 62, 432-437. [CrossRef]

94. Odnobokova, M.; Belyakov, A.; Kaibyshev, R. Development of Nanocrystalline 304L Stainless Steel by Large Strain Cold Working. Metals 2015, 5, 656-668. [CrossRef] 